\title{
Radioisotope and Metal Concentrations in Borehole Water Samples of Umuahia and Umudike, Nigeria
}

\author{
*NNAJI, JC; IGWE, OU; ONYEDIM, KM; OKAFOR, P \\ Department of Chemistry, Michael Okpara University of Agriculture, Umudike, P. M. B. 7267, Umuahia, Abia State, Nigeria. \\ *Corresponding Author Email: judennaji30@gmail.com
}

\begin{abstract}
The study examined metal and radioisotope concentrations in boreholes water samples collected from the neighbouring towns of in Umuahia and Umudike, Abia State, Nigeria. Triplicate samples were collected from seventeen functional boreholes and were analyzed with standard methods for physicochemical parameters. Metal concentrations were analyzed with Graphite furnace Atomic Absorption Spectrophotometer (AAS) while radioisotopes were determined with gamma ray spectrometry. Results showed that mean values for conductivity, total solids, total dissolved solids, hardness and nitrates were lower than recommended values by the World Health Organization (WHO) and Standards Organization of Nigeria (SON). However, mean values for $\mathrm{pH}$ (range: $3.05 \pm 0.11-4.51 \pm 0.08$ ) were in the acidic region and outside the recommended values. Mean metal concentrations had ranges of: calcium $1.255 \pm 0.037-$ $1.967 \pm 0.078 \mathrm{mg} / \mathrm{L}$; magnesium $0.286 \pm 0.057-0.608 \pm 0.094 \mathrm{mg} / \mathrm{L}$; sodium $0.030 \pm 0.005-0.102 \pm 0.029 \mathrm{mg} / \mathrm{L}$; iron $0.012 \pm 0.001-0.019 \pm 0.004 \mathrm{mg} / \mathrm{L}$; cadmium $0.001 \pm 0.000-0.011 \pm 0.003 \mathrm{mg} / \mathrm{L}$ and lead $(\mathrm{Pb}) 0.077 \pm 0.005-0.198 \pm 0.040$ $\mathrm{mg} / \mathrm{L}$. The mean concentrations of calcium, sodium, magnesium and iron were all below the NSDWQ limits. However, while mean cadmium concentrations exceeded SON limits in 13 locations, mean lead concentrations were above the limits set by WHO and SON in the samples from all the boreholes. The mean activity concentrations K-40, U-238 and Th-232 had ranges of below detection limit (BDL) $-21.94 \pm 2.50 \mathrm{~Bq} / \mathrm{L} ; \mathrm{BDL}-7.85 \pm 1.80 \mathrm{~Bq} / \mathrm{L}$ and $\mathrm{BDL}-5.76 \pm 0.53$ respectively. The SON maximum level for radionuclides in water is $0.1 \mathrm{~Bq} / \mathrm{L}$ while the WHO limits for U-238 and Th-232 are 10 and $1 \mathrm{~Bq} / \mathrm{L}$ respectively. The activity concentrations of U-238 were below the WHO limits but the limits were exceeded for Th-232 in water samples from eight locations. The NSDWQ limits were exceeded in samples from most of the locations for K-40.
\end{abstract}

DOI: $\underline{\text { https://dx.doi.org/10.4314/jasem.v23i7.32 }}$

Copyright: Copyright (C) 2019 Nnaji et al. This is an open access article distributed under the Creative Commons Attribution License (CCL), which permits unrestricted use, distribution, and reproduction in any medium, provided the original work is properly cited.

Dates: Received: 28 May 2019; Revised: 28 July 2019; Accepted 31 July 2019

Keywords: Metals, radioisotopes, water, Umuahia, Umudike,

Water is a crucial resource for the existence and survival of mankind and the importance of good quality drinking water cannot be over emphasized. A large portion of the world's population depends on groundwater (i.e. wells, bore holes) for their survival (Lenntech, 2004). The over exploitation of ground water resources and both natural and anthropogenic processes lead to the degradation of groundwater quality. Natural processes include the absorption of contaminants like heavy metals and naturally occurring radioactive materials (NORMs) from the soil while anthropogenic processes include seepage or direct migration of wastes generated from human activities from the soil into groundwater. Heavy metals are serious pollutants because of their toxicity, persistence and non degradability in the environment (Jarup, 2003). They are usually present in trace amounts in natural water but many of them are toxic even at very low concentrations. NORMs emits alpha, beta and gamma radiations but their activity concentrations depend on the water source; their activity concentration are typically low in surface water but drinking water from deep wells and boreholes usually have higher concentrations arising from the absorption of NORM when water passes through fractures in bedrocks or soil which may have mineral deposits with radioactive constituents (Gyuk et al., 2017). The major radionuclides that are naturally introduced into surface water and groundwater include uranium, thorium, radium-226, radium-228, radon, potassium-40, tritium, and carbon14. It is estimated that over $80 \%$ of the radiation doses received by humans arise from natural radiation sources especially the naturally occurring radioactive isotopes of U-238 and Th-232, their progeny and also K-40 (Shetty and Narayana, 2010; UNSCEAR, 1993).

The major source of drinking water in Umuahia and Umudike is mechanized boreholes. Therefore, this study both analyzes the physicochemical, metal and radionuclide concentrations in water samples from boreholes in both areas in order to determine their suitability for drinking.

*Corresponding Author Email: judennaji30@gmail.com 


\section{MATERIALS AND METHODS}

Study Area: The study was carried out in Umuahia and Umudike, Abia State, Nigeria. Umuahia is the capital of Abia State and is divided into Umuahia North and Umuahia South Local Government Areas (LGAs). Geographically, Umuahia is located within latitude: $5^{\circ}$ $32^{\prime} \mathrm{N}$ and longitude: $7^{\circ} 29^{\prime} \mathrm{E}$. and is within the forest belt. The area is characterized by high temperatures of about $29-31^{\circ} \mathrm{C}$ and has double maximal rainfall peaks in July and September. It has an area of $245 \mathrm{~km}^{2}$ and a population of 359,230 according to the 2006 National Population Census (NPC, 2006). Geologically, Umuahia is within the Benin formation which comprises of shale/sand sediments with intercalation of thin clay beds. It is a part of the coastal plain sands of the Cenozoic Niger Delta region of Nigeria.

Umudike is about $10 \mathrm{~km}$ southeast of Umuahia. It is in Ikwuano LGA which is endowed with rich agricultural land. Umudike is located between latitude $5^{\circ} 28^{\prime} 33^{\prime \prime} \mathrm{N}$ and longitude: $7^{\circ} 32^{\prime} 56^{\prime \prime} \mathrm{E}$ and it hosts the Michael Okpara University of Agriculture (MOUAU) and the National Root Crops Research Institute (NRCRI). The town is surrounded by other neighbouring communities which it shares it common beliefs and socio-cultural ethics with. These communities include Umuariaga, Amaoba, Amawom, Nnono, Ndoro and Ahuwa which accommodate a large percentage of the students of MOUAU. Major occupations include agriculture, trading and civil service.

Table 1. Sampling Point Description and Location

\begin{tabular}{|c|c|c|c|}
\hline $\begin{array}{l}\text { Sample } \\
\text { ID }\end{array}$ & $\begin{array}{l}\text { Sampling } \\
\text { Location }\end{array}$ & GPS Coordinates & Town \\
\hline 1 & NDDC Hostel (MOUAU) & $5.480969 \mathrm{~N}, 7.543423 \mathrm{E}$ & Sooudike \\
\hline 2 & New Hostel (MOUAU) & $5.480359 \mathrm{~N}, 7.539178 \mathrm{E}$ & \\
\hline 3 & Old Hostel (MOUAU) & $5.480666 \mathrm{~N}, 7.542379 \mathrm{E}$ & \\
\hline 4 & $\begin{array}{l}\text { Master Vessel, Jumuariaga, } \\
\text { Ikot-Elkpene Road }\end{array}$ & $5.475138 \mathrm{~N}, 7.547809 \mathrm{E}$ & \\
\hline 5 & Amawrom Village & $5.467268 \mathrm{~N}, 7.548389 \mathrm{E}$ & \\
\hline 6 & Ehimmiri (beside Smilemoore Hotel), Ikot-Epkene Road & $5.512794 \mathrm{~N}, 7.525433 \mathrm{E}$ & Umuahia \\
\hline 7 & No. 7 Agbazunuke St., World Bank Housing Estate & $5.514894 \mathrm{~N}, 7.503257 \mathrm{E}$ & \\
\hline 8 & No. 1 Ndoki/Health Centre Road, World Bank Housing Estate & $5.514319 \mathrm{~N}, 7.500580 \mathrm{E}$ & \\
\hline 9 & 117 Aba Rd (opposite Apricot Hotel) & $5.507337 \mathrm{~N}, 7.488238 \mathrm{E}$ & \\
\hline $\begin{array}{l}10 \\
11 \\
12 \\
13\end{array}$ & $\begin{array}{l}\text { Afara (Opp. Technical College) } \\
\text { No } 21 \text { Azikiwe Road } \\
\text { 26 Lagos Street/Calabar. Street } \\
\text { No. } 20 \text { Palm Lane }\end{array}$ & $\begin{array}{l}5.511531 \mathrm{~N}, 7.485180 \mathrm{E} \\
5.525740 \mathrm{~N}, 7.496130 \mathrm{E} \\
5.533935 \mathrm{~N}, 7.494303 \mathrm{E} \\
5.538036 \mathrm{~N}, 7.494018 \mathrm{E}\end{array}$ & \\
\hline 14 & $\begin{array}{l}\text { Opposite All Saints Church, } \\
\text { Eziama Ossa }\end{array}$ & $5.534399 \mathrm{~N}, 7.480370 \mathrm{E}$ & \\
\hline 15 & Qbowwo/OwerriRoad & $5.544526 \mathrm{~N}, 7.501661 \mathrm{E}$ & \\
\hline 16 & No. 149 Bende Road & $5.536120 \mathrm{~N}, 7.516460 \mathrm{E}$ & \\
\hline 17 & Qbovota Village & $5.511882 \mathrm{~N}, 7.529805 \mathrm{E}$ & \\
\hline
\end{tabular}

Sampling, Sample Pre-treatment and Preservation: A pre-sampling survey of the sampling areas (Umuahia North and Ikwuano LGAs) was conducted prior to sampling and this enabled the identification of functional boreholes. A Functional borehole was conceptualized as one that is regularly used by a minimum of 50 persons daily. Thirty-five functional boreholes were identified and stratified random sampling was applied in the selection of sampling points in order to achieve a fair representation of drinking water sources in both LGAs. Triplicate water samples were collected from each sampling point (borehole) with acid washed 2L polyethylene containers. Samples for heavy metal and radionuclide determination were acidified with $2 \mathrm{ml} / \mathrm{L}$ concentrated $\mathrm{HNO}_{3}$. The containers were tightly corked, labeled, put in an ice chest and immediately taken to the laboratory for analysis. The description and location of the sampling points are outlined in Table 1 while Figure 1 shows the map of the sampling areas.



Fig 1. Map showing the Sampling Points 
Analyses of Water Samples: Extech DO/temperature meter (model SDL 150) was calibrated with electrolyte filling solution and used for DO determination. Hanna portable $\mathrm{pH} /$ temp/EC/TDS meter (model HI991300) was calibrated with buffer 4, 7 and 9 solutions (for $\mathrm{pH}$ ) and 0.01 moldm $^{-3}$ potassium chloride solution (for electrical conductivity, EC). It was then used to determine $\mathrm{pH}$, temperature, $\mathrm{EC}$ and total dissolved solids (TDS) by inserting the probe into a pre-washed $250 \mathrm{ml}$ beaker containing each water sample at the point of collection after the beaker was rinsed thrice with the particular water samples.

Standard methods for the examination of water and wastewater (APHA, 2012) were used for other physicochemical parameters including total solids, hardness, alkalinity, nitrate and phosphate. Total Solids was determined by evaporation to dryness of $100 \mathrm{ml}$ of water sample while total hardness was determined with the ethylene diamine tetra acetic acid (EDTA) titrimetric method. Total alkalinity was determined with the titrimetric method using $0.02 \mathrm{M}$ $\mathrm{H}_{2} \mathrm{SO}_{4}$ and methyl orange indicator. The colorimetric method using a spectrophotometer was used for nitrate and phosphate determinations.

Metal Analysis: The metals of interest were sodium, calcium, magnesium, cadmium, lead and iron. Aqueous stock solutions were prepared with the appropriate metallic salts and five working standards were prepared in triplicate for each metal by serial dilution of the appropriate stock solutions. These and blank solutions were aspirated into an Atomic Absorption Spectrophotometer (model 210/211VGP) with a $220 \mathrm{GF}$ Graphite furnace 220 AS Autosampler. Absorbance readings obtained from Atomic Absorption Spectrophotometer (AAS) for each standard was used in plotting calibration curves for each metal. The samples were digested according to APHA (2012). 100ml of sample was transferred into a $250 \mathrm{ml}$ conical flask. $5 \mathrm{ml}$ of concentrated $\mathrm{HNO}_{3}$ and a few boiling chips were added. The solution was boiled slowly and evaporated on a hot plate to about $20 \mathrm{ml}$, before precipitation occurs. Heating and addition of concentrated $\mathrm{HNO}_{3}$ was continued until a clear solution was obtained. The sample was not allowed to dry during digestion. The wall of the flask was washed with distilled-deionised water and solution filtered through Whatman no. 42 filter paper into a $50 \mathrm{ml}$ volumetric flask with two $5 \mathrm{ml}$ portions of deionised water. The solution was cooled, made up to mark and mixed thoroughly. Portions of this solution were used for metal determinations with the AAS.

Determination of Radioisotopes by Gamma Ray Spectrometry: The gamma ray spectrometry analysis was carried out at the National Institute of Radiation Protection and Research (NIRPR), University of Ibadan, Nigeria. This was done using a Canberra NaI detector (model UNISPEC, serial no 22060316). Energy Calibration Sources were Am-241, Cs-137 and Co-60. The complete electronic instrumentation was connected to a PC-based multichannel analyser for gamma spectrum evaluation.

The energy and efficiency calibration of the $\mathrm{NaI}$ detector was carried out with IAEA Mixed Sediment Standard consisting of K-40, U-238 and Th-232 using the $1.33 \mathrm{MeV}$ gamma line of Co-60 resulting to energy resolution of $2.3 \mathrm{keV}$ (Full Width at Half Maximum, FWHM) with a relative yield of $1.73 \%$.

Each sample was put into an acid washed Marinelli beaker (cylindrical plastic container) which was firmly sealed for a minimum of $28 \mathrm{~d}$ in order for secular equilibrium to be attained. They were then counted for 10800s (3h) each after they had attained secular equilibrium. The gamma spectrum peak area analysis and quantification was done with Genie 2000 software.

The activity concentrations of the radionuclides (K-40, U-238 and Th-232) were determined using the equation:

$$
\mathrm{Ac}=\frac{\mathrm{Cn}}{\mathrm{P} \gamma \mathrm{V} \varepsilon}
$$

$\left(\mathrm{A}_{\mathrm{C}}=\right.$ activity concentration of the radionuclide in the sample in $\mathrm{Bq} / \mathrm{L} ; \mathrm{C}_{\mathrm{n}}=$ net count under the corresponding peak; $\mathrm{P} \gamma=$ absolute transition probability of the specific gamma ray; $\mathrm{V}=$ volume of the sample (L); $\varepsilon=$ detector efficiency at the specific gamma ray energy).

The data generated were converted to conventional units with calibration factors for actual determination of the activity concentrations the radionuclides. In order to determine the specific activity concentrations in the samples, the IAEA mixed standard which contains the radionuclides of the same dimension as the samples were also subjected to the same experimental procedures followed by subtraction of background counts. Generation of activity concentration in $\mathrm{Bq} / \mathrm{L}$ was then carried out via the conversion of the count per second with the conversion factors which were different for each nuclide.

\section{RESULTS AND DISCUSSION}

Physicochemical Analysis: The physico-chemical parameters of the groundwater samples are shown in Table 2. Temperature ranged from $26.41 \pm 0.27$ in Sample 1 to $29.20 \pm 0.09^{\circ} \mathrm{C}$ in Sample 8. This suggests 
that the groundwater temperature is generally ambient and good for consumers who prefer cool to warm water. High temperature negatively impacts water quality by enhancing the growth of certain microorganisms which may increase taste, odour, colour and corrosion problems (UNICEF, 2008). Electrical conductivity (EC) values had a range of $37.09 \pm 2.50-$ $601.00 \pm 15.30 \mu \mathrm{S} / \mathrm{cm}$. Electrical conductivity gives an indication of the amount of total dissolved ions in water (Yilmaz and Koc, 2014). Mean values for EC in all the samples were low compared to the standard value $1000 \mu \mathrm{S} / \mathrm{cm}$ set by and the World Health Organization, WHO (2017). The $\mathrm{pH}$ values of all the water samples were in the acidic region and ranged from $3.05 \pm 0.11$ in sample 5 to $4.51 \pm 0.08$ in sample 14 . WHO recommends a $\mathrm{pH}$ range of 6.5-8.5 for drinking water though a $\mathrm{pH}$ above 8.0 would be disadvantageous in the treatment and disinfection of drinking water with chlorine (UNICEF, 2008). Water samples gotten from various locations in Umuahia and Umudike were acidic and much lower than the WHO guideline values. Possible implication of this scenario is that low $\mathrm{pH}$ levels can encourage the solubility of heavy metals in water from piping and storage systems. Acidic water can also impart sour or metallic taste on drinking water and lead to staining of laundry and sinks.

Mean total solid (TS) content had a range of $40.23 \pm 3.50-410.93 \pm 12.88 \mathrm{mg} / \mathrm{L}$ while mean total dissolve solids (TDS) ranged from $18.13 \pm 1.24$ in Sample 1 to $301.58 \pm 6.35 \mathrm{mg} / \mathrm{L}$ in Sample 13. Mean TDS values in all the samples were below the WHO and Nigeria Standards for Drinking Water Quality (SON, 2015) recommended values of 1000 and 500 $\mathrm{mg} / \mathrm{L}$ respectively. The dissolved oxygen (DO) is oxygen that is dissolved in water. Dissolved oxygen analysis measures the amount of gaseous oxygen $\left(\mathrm{O}_{2}\right)$ dissolved in an aqueous solution. Oxygen gets into water by diffusion from the surrounding air, by aeration (rapid movement), and as a waste product of photosynthesis. Mean DO values of the samples ranged from $3.84 \pm 0.17$ to $7.45 \pm 0.92 \mathrm{mg} / \mathrm{L}$. A high DO level in a community water supply is good because it makes drinking water taste better. However, high DO levels may enhance corrosion in water pipes. For this reason, industries use water with the least possible amount of dissolved oxygen.

Table 2. Mean Physicochemical Parameters of Borehole Water Samples

\begin{tabular}{|c|c|c|c|c|c|c|c|c|c|c|}
\hline $\begin{array}{l}\text { Sample } \\
\text { ID }\end{array}$ & $\begin{array}{l}\text { Temp } \\
\left({ }^{\circ} \mathrm{C}\right)\end{array}$ & $\begin{array}{l}\mathrm{EC} \\
(\mu \mathrm{S} / \mathrm{cm})\end{array}$ & $\mathrm{pH}$ & $\begin{array}{l}\text { TS } \\
\text { (mg/L) }\end{array}$ & $\begin{array}{l}\text { TDS } \\
(\mathrm{mg} / \mathrm{L})\end{array}$ & $\begin{array}{l}\text { DO } \\
(\mathrm{mg} / \mathrm{L})\end{array}$ & $\begin{array}{l}\text { Hardness } \\
\left(\mathbf{m g C a C O}_{3} \mathbf{L}\right)\end{array}$ & $\begin{array}{l}\text { Alkalinity } \\
\text { (mg/L) }\end{array}$ & $\begin{array}{l}\mathrm{NO}_{3}^{-} \\
(\mathrm{mg} / \mathrm{L})\end{array}$ & $\begin{array}{l}\mathrm{PO}^{3-} \\
(\mathrm{mg} / \mathrm{L})\end{array}$ \\
\hline 1 & $26.41 \pm 0.27$ & $37.09 \pm 2.50$ & $4.35 \pm 0.18$ & $40.23 \pm 3.50$ & $8.13 \pm 1.24$ & $7.45 \pm 0.92$ & $9.20 \pm 1.27$ & $181.05 \pm 7.49$ & $0.06 \pm 0.00$ & $2.33 \pm 0.82$ \\
\hline 2 & $26.64 \pm 0.16$ & $123.20 \pm 3.22$ & $3.66 \pm 0.45$ & $113.56 \pm 5.81$ & $61.27 \pm 3.28$ & $4.82 \pm 0.61$ & $22.56 \pm 2.70$ & $163.11 \pm 4.57$ & $0.01 \pm 0.00$ & $1.57 \pm 0.07$ \\
\hline 3 & $27.43 \pm 0.50$ & $233.15 \pm 1.71$ & $3.35 \pm 0.07$ & $200.42 \pm 11.12$ & $116.52 \pm 5.71$ & $5.10 \pm 0.33$ & $241.18 \pm 10.15$ & $26.94 \pm 1.88$ & $0.12 \pm 0.01$ & $2.10 \pm 0.11$ \\
\hline 4 & $27.40 \pm 0.22$ & $343.22 \pm 5.86$ & $3.12 \pm 0.03$ & $295.21 \pm 10.77$ & $169.11 \pm 8.20$ & $4.68 \pm 0.11$ & $153.25 \pm 7.71$ & $30.72 \pm 2.99$ & $0.18 \pm 0.02$ & $2.59 \pm 0.08$ \\
\hline 5 & $26.91 \pm 0.63$ & $350.06 \pm 9.25$ & $3.05 \pm 0.11$ & $301.63 \pm 15.36$ & $169.70 \pm 4.29$ & $4.63 \pm 0.15$ & $20.49 \pm 1.83$ & $150.83 \pm 4.11$ & $0.01 \pm 0.00$ & $1.53 \pm 0.07$ \\
\hline 6 & $27.12 \pm 0.11$ & $187.24 \pm 6.14$ & $3.32 \pm 0.04$ & $164.28 \pm 9.83$ & $94.38 \pm 5.82$ & $4.86 \pm 0.63$ & $212.84 . \pm 12.10$ & $26.15 \pm 2.74$ & $0.11 \pm 0.02$ & $3.22 \pm 0.41$ \\
\hline 7 & $28.15 \pm 0.04$ & $347.81 \pm 2.88$ & $3.09 \pm 0.02$ & $311.84 \pm 11.90$ & $174.21 \pm 9.18$ & $4.25 \pm 0.09$ & $128.39 \pm 5.81$ & $18.50 \pm 1.90$ & $0.14 \pm 0.01$ & $1.60 \pm 0.08$ \\
\hline 8 & $29.27 \pm 0.09$ & $111.25 \pm 7.83$ & $4.27 \pm 0.61$ & $101.20 \pm 14.89$ & $56.88 \pm 6.41$ & $4.49 \pm 0.13$ & $18.77 \pm 1.95$ & $115.32 \pm 5.18$ & $0.19 \pm 0.05$ & $1.92 \pm 0.21$ \\
\hline 9 & $27.73 \pm 0.39$ & $113.70 \pm 4.72$ & $4.23 \pm 0.07$ & $116.05 \pm 6.44$ & $56.19 \pm 2.77$ & $4.42 \pm 0.07$ & $11.96 \pm 1.33$ & $180.22 \pm 7.59$ & $1.81 \pm 0.34$ & $2.10 \pm 0.14$ \\
\hline 10 & $28.52 \pm 0.62$ & $127.55 \pm 3.11$ & $4.25 \pm 0.19$ & $123.19 \pm 12.70$ & $64.26 \pm 1.90$ & $4.37 \pm 0.15$ & $23.14 \pm 4.09$ & $170 \pm 11.28$ & $0.02 \pm 0.00$ & $2.05 \pm 0.35$ \\
\hline 11 & $27.48 \pm 0.18$ & $134.74 \pm 7.94$ & $4.06 \pm 0.02$ & $103.68 \pm 4.61$ & $67.35 \pm 5.21$ & $4.82 \pm 0.31$ & $25.42 \pm 2.70$ & $149.56 \pm 6.44$ & $0.29 \pm 0.04$ & $3.06 \pm 0.77$ \\
\hline 12 & $27.33 \pm 0.19$ & $484.19 \pm 10.11$ & $3.91 \pm 0.02$ & $357.28 \pm 25.26$ & $248.17 \pm 4.99$ & $4.89 \pm 0.20$ & $115.74 \pm 13.67$ & $15.99 \pm 3.27$ & $0.57 \pm 0.01$ & $1.84 \pm 0.69$ \\
\hline 13 & $28.41 \pm 0.80$ & $601.20 \pm 15.30$ & $3.89 \pm 0.11$ & $410 \pm 12.88$ & $301.58 \pm 6.35$ & $3.84 \pm 0.17$ & $169.33 \pm 8.31$ & $370.14 \pm 14.22$ & $0.03 \pm 0.00$ & $1.50 \pm 0.23$ \\
\hline 14 & $28.15 \pm 0.07$ & $89.52 \pm 5.29$ & $4.51 \pm 0.08$ & $100.29 \pm 5.45$ & $45.29 \pm 1.22$ & $4.72 \pm 0.02$ & $29.17 \pm 2.88$ & $177.35 \pm 12.16$ & $0.21 \pm 0.01$ & $0.98 \pm 0.03$ \\
\hline 15 & $26.95 \pm 0.21$ & $63.26 \pm 1.88$ & $3.46 \pm 0.03$ & $59.48 \pm 2.19$ & $32.60 \pm 0.76$ & $4.46 \pm 0.33$ & $20.11 \pm 1.85$ & $139.46 \pm 3.22$ & $0.08 \pm 0.00$ & $1.81 \pm 0.50$ \\
\hline 16 & $27.53 \pm 0.54$ & $45.85 \pm 1.53$ & $3.54 \pm 0.01$ & $45.33 \pm 2.30$ & $22.94 \pm 0.93$ & $5.81 \pm 0.86$ & $10.28 \pm 1.13$ & $180.09 \pm 10.55$ & $0.04 \pm 0.00$ & $2.36 \pm 0.47$ \\
\hline 17 & $27.11=0.49$ & $62.10 \pm 3.44$ & $4.08 \pm 0.04$ & $73.27 \pm 3.15$ & $31.71 \pm 0.88$ & $4.39 \pm 0.19$ & $17.59 \pm 2.82$ & סתדתוים & $1.07 \pm 0.03$ & $0.85 \pm 0.04$ \\
\hline \multicolumn{11}{|l|}{ WHO } \\
\hline $\begin{array}{l}\text { limits } \\
(2017)\end{array}$ & Cool & - & 6. & - & 1000 & - & - & - & 50 & - \\
\hline $\begin{array}{l}\text { SON } \\
\text { limits } \\
(2015)\end{array}$ & Ambient & - & $6.5-8.5$ & - & 500 & - & 150 & - & 50 & - \\
\hline
\end{tabular}

$W H O=$ World Health Organization recommended Values; SON = Standards Organization of Nigeria

Metal Analysis: The results for the mean concentrations of metals $(\mathrm{Na}, \mathrm{mg}, \mathrm{Ca}, \mathrm{Fe}, \mathrm{Pb}$ and $\mathrm{Cd})$ in the water samples collected from the 17 boreholes in Umuahia and Umudike are presented in Table 3. Mean calcium concentration ranged from $1.255 \pm 0.037$ $\mathrm{mg} / \mathrm{L}$ in location 1 (NDDC Hostel, MOUAU) to $1.967 \pm 0.078 \mathrm{mg} / \mathrm{L}$ in location 3 (Old Hostel, MOUAU). These values were all below the guideline values of WHO. Calcium occurs in water naturally and one of the main reasons for its abundance in water is its natural occurrence in the earth's crust. Calcium is an important determinant of water harness, and it also functions as a $\mathrm{pH}$ stabilizer, because of its buffering qualities. Calcium also gives water a better taste but in addition to its contribution to water hardness, several epidemiological investigations have demonstrated the 
relation between risk for cardiovascular disease, growth retardation, reproductive failure, and other health problems is caused by drinking water having venteen different sampling locations ranged from $0.001 \pm 0.000$ in location 10 to $0.011 \pm 0.003 \mathrm{mg} / \mathrm{L}$ in location 7 . large Ca content. Mean cadmium concentrations of the borehole water samples from the se

Table 3. Mean Metal Concentrations in Borehole Water Samples

\begin{tabular}{lllllll}
\hline \multirow{2}{*}{ Sample ID } & \multicolumn{5}{c}{ Metals concentrations (mg/) } \\
\cline { 2 - 7 } & $\mathrm{Ca}$ & $\mathrm{Cd}$ & $\mathrm{Fe}$ & $\mathrm{Ph}$ & $\mathrm{Na}$ & $\mathrm{Mg}$ \\
\hline 1 & $1.255 \pm 0.037$ & $0.009 \pm 0.000$ & $0.012 \pm 0.001$ & $0.191 \pm 0.028$ & $0.048 \pm 0.011$ & $0.286 \pm 0.057$ \\
2 & $1.360 \pm 0.101$ & $0.006 \pm 0.001$ & $0.014 \pm 0.003$ & $0.171 \pm 0.033$ & $0.038 \pm 0.007$ & $0.401 \pm 0.082$ \\
3 & $1.967 \pm 0.078$ & $0.008 \pm 0.002$ & $0.014 \pm 0.001$ & $0.149 \pm 0.017$ & $0.084 \pm 0.015$ & $0.348 \pm 0.071$ \\
4 & $1.867 \pm 0.211$ & $0.005 \pm 0.000$ & $0.017 \pm 0.003$ & $0.155 \pm 0.022$ & $0.051 \pm 0.018$ & $0.309 \pm 0.029$ \\
5 & $1.298 \pm 0.065$ & $0.002 \pm 0.000$ & $0.015 \pm 0.002$ & $0.144 \pm 0.019$ & $0.065 \pm 0.009$ & $0.554 \pm 0.095$ \\
6 & $1.783 \pm 0.127$ & $0.009 \pm 0.001$ & $0.015 \pm 0.000$ & $0.077 \pm 0.005$ & $0.041 \pm 0.006$ & $0.359 \pm 0.037$ \\
7 & $1.647 \pm 0.311$ & $0.011 \pm 0.003$ & $0.012 \pm 0.002$ & $0.164 \pm 0.026$ & $0.043 \pm 0.010$ & $0.464 \pm 0.085$ \\
8 & $1.464 \pm 0.094$ & $0.006 \pm 0.001$ & $0.019 \pm 0.004$ & $0.160 \pm 0.044$ & $0.057 \pm 0.018$ & $0.413 \pm 0.038$ \\
9 & $1.366 \pm 0.072$ & $0.003 \pm 0.000$ & $0.012 \pm 0.001$ & $0.127 \pm 0.011$ & $0.102 \pm 0.029$ & $0.379 \pm 0.077$ \\
10 & $1.300 \pm 0.088$ & $0.001 \pm 0.000$ & $0.015 \pm 0.003$ & $0.189 \pm 0.063$ & $0.068 \pm 0.007$ & $0.572 \pm 0.062$ \\
11 & $1.779 \pm 0.116$ & $0.004 \pm 0.001$ & $0.012 \pm 0.002$ & $0.194 \pm 0.071$ & $0.083 \pm 0.027$ & $0.409 \pm 0.016$ \\
12 & $1.271 \pm 0.240$ & $0.005 \pm 0.001$ & $0.019 \pm 0.004$ & $0.198 \pm 0.040$ & $0.073 \pm 0.013$ & $0.499 \pm 0.022$ \\
13 & $1.496 \pm 0.129$ & $0.006 \pm 0.000$ & $0.013 \pm 0.001$ & $0.174 \pm 0.029$ & $0.082 \pm 0.024$ & $0.347 \pm 0.028$ \\
14 & $1.385 \pm 0.447$ & $0.005 \pm 0.001$ & $0.014 \pm 0.003$ & $0.158 \pm 0.016$ & $0.062 \pm 0.018$ & $0.497 \pm 0.011$ \\
15 & $1.462 \pm 0.097$ & $0.007 \pm 0.002$ & $0.015 \pm 0.004$ & $0.168 \pm 0.032$ & $0.086 \pm 0.030$ & $0.518 \pm 0.103$ \\
16 & $1.265 \pm 0.046$ & $0.000 \pm 0.000$ & $0.014 \pm 0.001$ & $0.200 \pm 0.047$ & $0.078 \pm 0.017$ & $0.608 \pm 0.094$ \\
17 & $1.353 \pm 0.085$ & $0.008 \pm 0.002$ & $0.017 \pm 0.002$ & $0.128 \pm 0.009$ & $0.030 \pm 0.005$ & $0.478 \pm 0.045$ \\
WHO limits (2017 & - & 0.003 & - & 0.01 & - & - \\
SON limits (2015) & - & 0.003 & 0.3 & 0.01 & 200 & 20 \\
\hline
\end{tabular}

The maximum permissible limits set by WHO and $\mathrm{SON}$ is $0.003 \mathrm{mg} / \mathrm{L}$ and this values is exceeded in water samples from locations $1,2,3,4,6,7,8,11,12,13$, 14,15 and 17. High concentration of cadmium in water for drinking and domestic purpose can cause severe damage to lungs and also cause diarrhea, severe stomach pain and vomiting (NAS, 1977). The mean concentrations of iron in the samples varied from $0.012 \pm 0.001$ to $0.019 \pm 0.004 \mathrm{mg} / \mathrm{L}$ which was lower that the SON guideline value of $0.03 \mathrm{mg} / 1$. WHO considers iron to be a secondary contaminant in drinking water which is not of health concern at levels causing acceptability problems. Mean lead concentrations had a range of $0.077 \pm 0.005$ $0.198 \pm 0.040 \mathrm{mg} / \mathrm{L}$. all the values exceed the permissible limit of $0.01 \mathrm{mg} / \mathrm{L}$ set by SON and WHO. Lead is a confirmed carcinogen which also interferes with the functions of vitamin $\mathrm{D}$ as well as damages the nervous system and causes brain disorder Jarup, 2003; Barbee and Prince, 1999). Mean sodium and magnesium concentrations had ranges of $0.030 \pm 0.005$ $-0.102 \pm 0.029 \mathrm{mg} / \mathrm{L}$ and $0.286 \pm 0.057-0.608 \pm 0.094$ $\mathrm{mg} / \mathrm{L}$ respectively. These concentrations were below the standards set for sodium $(200 \mathrm{mg} / \mathrm{L})$ and magnesium $(20 \mathrm{mg} / \mathrm{L})$ by SON. Magnesium, like calcium, causes hardness of water. It is more difficult for hard water to form latter with soap. The most common effects of hard water on the human skin is dryness and difficulty in rinsing away soap from the surface of the skin which leaves the skin dry and potentially irritated. 
for K-40. The radiation impact risk on biota depends on factors like the type of radiation involved, energy of radiation, activity level, the chemical and physical properties of the nuclides and the contaminated material (NAS, 1977).

\begin{tabular}{|c|c|c|c|}
\hline Sample ID & $\mathrm{K}-40(\mathrm{Ba} / \mathrm{L})$ & $\mathrm{U}-238(\mathrm{Ba} / \mathrm{L})$ & Th-232 (Ba/L \\
\hline 1 & $10.95 \pm 0.98$ & $7.85=1.80$ & $\overline{B D L}$ \\
\hline 2 & $1.59=0.14$ & $4.64 \pm 1.01$ & $4.11=0.37$ \\
\hline 3 & $21.79 \pm 1.89$ & $5.73=1.28$ & $5.76 \pm 0.53$ \\
\hline 4 & $12.68=1.06$ & $4.76 \pm 1.19$ & $1.56 \pm 0.17$ \\
\hline 5 & BDL & $5.45 \pm 1.22$ & BDL \\
\hline 6 & BDL & BDL & BDL \\
\hline 7 & BDL & BDL & $0.78 \pm 0.08$ \\
\hline 8 & $2.99=0.27$ & $4.24=0.95$ & $4.24=0.95$ \\
\hline 9 & $29.68=2.25$ & $\mathrm{BDL}$ & BDL \\
\hline 10 & $2.19=0.18$ & $3.50=0.80$ & $1.19=0.12$ \\
\hline 11 & $2.10=0.18$ & BDL & BDL \\
\hline 12 & $6.57 \pm 0.56$ & $5.27 \pm 1.21$ & $1.23=0.12$ \\
\hline 13 & $13.14=1.05$ & $0.23 \pm 0.07$ & BDL \\
\hline 14 & $5.99=0.51$ & BDL & $1.53=0.05$ \\
\hline 15 & $21.94 \pm 2.50$ & $4.82=0.64$ & $1.53=0.09$ \\
\hline 16 & $8.70=0.75$ & $7.11=1.62$ & BDL \\
\hline 17 & $1.73=0.15$ & BDL & BDL \\
\hline WHO limits (2017) & - & 10.00 & 1.00 \\
\hline \multicolumn{3}{|c|}{ SON (2015) maximum level for radiomuclides } & 0.1 \\
\hline
\end{tabular}

The United Nations Scientific Committee on Effects of Atomic Radiation, UNSCEAR, reported that the average worldwide exposure to natural sources in foods and drinking water (ingestion exposure) is 0.29 $\mathrm{mSv} / \mathrm{y}$ i.e. approximately $0.17 \mathrm{mSv} / \mathrm{y}$ from $\mathrm{K}-40$ and $0.12 \mathrm{mSv} / \mathrm{y}$ from Uranium and Thorium (UNSCEAR, 2000). Minute traces of radioactivity normally exist in all drinking water but concentrations depend on the radiochemical composition of soils and rocks strata through which raw passes and this makes compositions in water to vary from place to place (NAS, 1977).

Conclusion: Water samples from boreholes in Umuahia and Umudike were all acidic and may need to be treated to bring $\mathrm{pH}$ up to the recommended range before consumption. Of greater concern are the values for mean cadmium concentrations which were above recommended limits in 13 out of the 17 sampled boreholes and lead concentrations which exceeded both national and international standards in all the samples. The limit set for Th-232 in water samples by WHO was also exceeded in eight locations while SON limit for K-40 was also exceeded in samples from most of the boreholes.

\section{REFERENCES}

APHA (2012). Standard Methods for the Examination of Water and Waste Water. 22nd Edition, American Public Health Association, American Water Works Association, Water Environment Federation, Washington DC.
Barbee, JYJ; Prince, TS (1999). Acute respiratory distress syndrome in awelder exposed to metal fumes. South Med. J. 92:510-520.

Gyuk, PM; Kassimu, AA; Daniel, IH; Bitrus, A; Arome, A; Jude A (2017). Analysis of Gross Alpha Radioactivity in Well Water in some Parts of Kaduna South and Environs, Nigeria. Int. J. Res. 5(9): 124-131

Jarup, L (2003). Hazards of heavy metal contamination. British Med. Bull. 68:167-182.

Jibiri, NN; Amakom, CM; Adewuyi, GO (2010). Radionuclide Contents and Physicochemical Water Quality Indicators in Stream, Well and Borehole Water Sources in High Radiation Area of Abeokuta, Southwestern Nigeria. J. Water Resour. Protec. 2(4): 291-297

Lenntech (2004). Water Treatment and Air Purification,Published by Lenntech, Rotterdamseweg, Netherland. www.excelwater.com/thp/filters/WaterPurification.htm Accessed 1 ${ }^{\text {st }}$ July, 2019

NAS (1977). Drinking Water and Health. Safe Drinking Water Committee, National Academy of Sciences, Washington, D.C. P 857

National Population Commission (NPC) (2006). Population and Housing Census, "Population 
distribution by Sex, State, LGA, and Senatorial district". http://www.population.gov.ng/images/ SDistrict-PDF.pdf Accessed 1 ${ }^{\text {st }}$ July, 2019

Norse Decom (2003). Naturally occurring radionuclides in the marine environment - an overview of current knowledge with emphasis on the North Sea area - Report: ND/E-19/03. Norse Decom, Kjeller, Norway. Pp. $26-48$

Shetty, PK; Narayana, Y (2010). Variation of radiation level and radionuclides enrichment in high background area. J. Environ. Radio. 101, $1043 \mathrm{e} 1047$

SON (2015). Nigerian Standard for Drinking Water Quality. Standards Organization of Nigeria, Abuja. Pp 17-22

UNICEF (2008). UNICEF Handbook on Water Quality. United Nations Children's Fund, New York. P 179
UNSCEAR (1993). Sources and effects of ionizing radiation. Report of the United Nations Scientific Committee on the Effects of Atomic Radiation to the general assembly. United Nations, New York. Pp 17-26

UNSCEAR (2000). (United Nations Scientific Committee on Effects of Atomic Radiation). Reports of General Assembly. Report Vol. 1. Sources and Effects of ionizing Radiation. United Nations, New York. Pp 36-42

WHO (2017). Guidelines for drinking-water quality: fourth edition incorporating the first addendum. World Health Organization, Geneva. Pp 468-475

Yilmaz, E; Koc, C (2014). Physically and chemically evaluation for the water quality criteria in a farm on Akcay. J. Water Resour. Prot. 6: 63-67. 